\title{
Effects of Host Resistance, Temperature, Leaf Wetness, and Leaf Age on Infection and Lesion Development of Pecan Scab
}

\author{
W. W. Turechek and K. L. Stevenson
}

First author: Department of Plant Pathology, The Ohio State University, Ohio Agricultural Research and Development Center, Wooster 44691; and second author: Department of Plant Pathology, University of Georgia, Athens 30602-7274. Accepted for publication 29 August 1998.

\begin{abstract}
Turechek, W. W., and Stevenson, K. L. 1998. Effects of host resistance, temperature, leaf wetness duration, and leaf age on infection and lesion development of pecan scab. Phytopathology 88:1294-1301.

The effects of partial host resistance, temperature, leaf wetness duration, and leaf age on infection and lesion development of pecan scab were evaluated. Trees of cultivars Wichita (susceptible) and Sumner (resistant) were inoculated with conidia of Cladosporium caryigenum and placed in mist chambers set at 15,25 , or $35^{\circ} \mathrm{C}$. The trees were removed from the chambers after $3,6,12,24,36$, or $48 \mathrm{~h}$ of leaf wetness and placed in a greenhouse to allow disease development. After 8 to 16 days, disease began to

develop on both 'Wichita' and 'Sumner'. Logistic regression analysis showed that the probability of a leaf becoming infected was greatest for 'Wichita'; it decreased with increasing leaf age and temperature and increased with increasing leaf wetness. Leaves on 'Wichita' were susceptible to infection between 2 and 23 days after budbreak, while leaves on 'Sumner' were susceptible to infection from 2 to 18 days after budbreak. Infection frequency, lesion size, and conidia production decreased proportionately with increasing leaf age. The magnitude of this effect was greatest on 'Sumner'. Conidia production was positively correlated with lesion size, and both were positively correlated with infection frequency on both cultivars.
\end{abstract}

In the southeastern United States, pecan scab, caused by the fungus Cladosporium caryigenum (Ell. et Lang) Gottwald (11), is the most destructive and commercially important disease of the pecan, Carya illinoensis (Wang.) K. Koch $(10,11)$. Conditions for fungal infection and disease development depend upon many factors and, as a result, disease intensities and losses vary from year to year $(1,2)$. Although scab-resistant cultivars are available and commonly planted, many resistant cultivars still require regular applications of fungicides that are applied on a calendar-based schedule. Minimizing economic losses due to scab could be facilitated by tailoring management practices to cultivars with specific levels of resistance. However, little is known about the influence of host resistance on fungal infection and disease development and, as a result, fungicide applications, as well as many other control practices, are not modified to account for host resistance.

Partial resistance to pecan scab is expressed in many cultivars. It can be manifested as a reduced ability of the pathogen to infect, colonize, or reproduce on the host. Partial resistance is typically quantified by measures such as infection frequency, incubation period, lesion size, and spore production $(17,28)$. These measures, typically referred to as components of resistance, have been studied in many pathosystems $(7,13,16,18,21)$. Many factors, aside from the genetic element of resistance, affect the expression of resistance components. The largest variations have been observed with fluctuations of temperature, leaf wetness, or both, in the form of high relative humidity or free moisture $(3,22,29,30)$. Variations also have been observed with differences in leaf age or growth stage of the plant $(7,19,25)$. It is often the case that no one factor alone is responsible for the expression of partial resistance, but it is the cumulative action of heredity, physiology, and the environment that are responsible for variations in field resistance.

Corresponding author: W. W. Turechek; E-mail address: turechek.1@osu.edu

Publication no. P-1998-1026-02R

(C) 1998 The American Phytopathological Society
Most of the epidemiological research on pecan scab has been done using seedlings of highly susceptible cultivars. In a significant study, Gottwald (12) determined that $48 \mathrm{~h}$ of leaf wetness at $25^{\circ} \mathrm{C}$ were the optimum environmental conditions to screen inoculated seedlings for resistance to pecan scab. However, most new orchards are planted to grafted cultivars, not seedlings. Because the pecan is cross-pollinated, the genetic makeup of seedlings is unknown and variable and, as a result, many traits of a seedling, including the response to pathogen attack, may differ greatly from its parents. In other words, experimental results obtained from seedlings may not accurately reflect the results one would obtain from using true cultivars. However, because of the lack of epidemiological information, Gottwald's results are often used as a benchmark to represent the minimum temperature and leaf wetness conditions necessary for fungal infection of pecan leaves in an orchard environment.

The absence of any quantitative measure of host resistance and the specific environmental conditions required for infection and disease development are lacking for resistant cultivars. Many studies have demonstrated that the response to pathogen attack, as characterized through the components of resistance, can vary tremendously among cultivars with varying levels of resistance $(13,17)$. Identifying and quantifying important resistance components aids in the understanding of disease dynamics. This kind of information can be used to target key stages of an epidemic and may allow tailoring of spray programs or disease forecasts to cultivars with different levels of scab resistance. This is particularly important for orchard-grown crops, such as the pecan, that require large quantities and frequent applications of fungicides to control disease.

The objectives of this research were to (i) examine the effects of cultivar resistance, temperature, leaf wetness duration, and leaf age on infection of pecan leaves by $C$. caryigenum; and (ii) determine the interrelationship among resistance components including infection frequency, incubation period, lesion size, and spore production in two pecan cultivars. 


\section{MATERIALS AND METHODS}

Cultivar preparation. Pecan trees (2 years old) of the cultivars Wichita and Sumner grafted on seedling rootstocks were purchased from commercial nurseries. Portions of the tap root and scion were cut just prior to planting in $45-\mathrm{cm}$-diameter plastic containers. The trees were planted in a 1:1:1 ( $\mathrm{vol} / \mathrm{vol} / \mathrm{vol})$ mixture of soil, sand, and pine bark and placed in the greenhouse. The trees were watered as needed and fertilized weekly with a water-soluble fertilizer (20:20:20, $\mathrm{N}-\mathrm{P}-\mathrm{K}$ ). Before each trial, all leaves were removed from the trees to stimulate the production of new foliage and ensure uniformity in leaf age. To encourage budbreak, the temperature was kept at a minimum of $29.5^{\circ} \mathrm{C}(24)$. New leaves were tagged as they emerged from the buds. The age of an individual leaf at the time of inoculation was recorded as the number of days between budbreak and inoculation.

Inoculum preparation. Leaves were harvested from 'Wichita' pecan trees at the University of Georgia Horticulture Farm near Watkinsville, GA. Newly formed scab lesions were cut from the leaves with a cork borer and swabbed across a petri dish containing 2\% water agar amended with the antibiotics streptomycin, tetracycline, and chloramphenicol, each at a concentration of $50 \mu \mathrm{g} / \mathrm{ml}$ of agar, to inhibit bacterial growth. After 16 to $20 \mathrm{~h}$ of incubation at 20 to $24^{\circ} \mathrm{C}$, single germinated conidia were transferred to potato dextrose agar (PDA) amended with antibiotics at the same concentration as the water agar. Three conidia were placed on each plate, and the plates were wrapped with Parafilm and placed in an incubator at $24^{\circ} \mathrm{C}$. A 12 -h photoperiod was maintained in the incubator with two 15-W General Electric cool-white fluorescent light bulbs.

To maximize conidia production, individual 6- to 8-week-old colonies were homogenized in $7.5 \mathrm{ml}$ of autoclaved deionized water with a tissue homogenizer (Tekmar Ultra Turrax; IKA Works, Inc., Wilmington, NC) and dispensed in 750- $\mu$ l aliquots over 10 oatmeal agar plates. The plates, without Parafilm, were incubated at $24^{\circ} \mathrm{C}$ for 5 to 10 days. A $0.1 \%$ Tween-20 solution $(5 \mathrm{ml})$ was dispensed on each petri dish, and the conidia were liberated into suspension by lightly brushing the surface with a glass rod. The suspension was strained through cheesecloth, and the conidia concentration was adjusted to 100,000 conidia per $\mathrm{ml}$ with a hemacytometer.

Inoculation. Using a low-pressure spray bottle, the inoculum suspension was applied to the upper surface of leaves on each tree until runoff. Controls were sprayed with a $0.1 \%$ Tween- 20 solution. Trees were randomly placed into one of three growth chambers, and continuous leaf wetness was maintained with an overhead misting system. The growth chambers were set at 15,25 , or $35^{\circ} \mathrm{C}$ and were kept in constant darkness. In the first trial, one tree from each cultivar in each growth chamber was removed after a leaf wetness period of $3,6,12,24$, and $36 \mathrm{~h}$. Because no disease developed after 3 or $6 \mathrm{~h}$ of leaf wetness in the first trial, trees in the second trial were removed after $6,12,24,36$, and $48 \mathrm{~h}$. In the third trial, trees were removed after 24, 36, and $48 \mathrm{~h}$. Fewer treatments were applied in the third trial because several pecan trees failed to develop new foliage after manual defoliation of the pecan leaves after the second trial. Three control plants of each cultivar were removed after the longest leaf wetness period in each trial. The controls served as a check for the inoculation procedure. The trees were transferred to the greenhouse, and disease was allowed to develop.

Assessment of disease and components of resistance. Individual leaves were examined daily for the appearance of lesions. The incubation period was recorded as the time (in days) from inoculation to the appearance of symptoms. The latent period usually is of more direct interest; however, there is often a direct relationship between the latent period and incubation period (17). The latent period was not recorded because destructive sampling of leaves would be necessary to determine if sporulation occurred on the resistant cultivar Sumner. Disease incidence was assessed 12 to 15 days after the appearance of symptoms. The infection fre- quency was measured by dividing the number of sporulating lesions per leaf by the area of the leaf. Leaf area, measured in square centimeters, was calculated using an electronic leaf area meter (model LI-3100; Li-Cor, Inc., Lincoln, NE). Mean lesion area was determined by excising 1 to 15 lesions (depending on the number of lesions present) from each diseased leaf, measuring the diameter of each lesion $(\mathrm{mm})$, and averaging their areas. Lesion area was calculated using the formula for the area of a circle.

To measure conidia production, excised lesions were placed in a microcentrifuge tube with $750 \mu$ of a $0.1 \%$ Tween-20 solution and mixed with a vortex mixer at high speed for 1 min to dislodge and suspend the conidia. Excised lesions were removed, and the suspension was centrifuged at $4,000 \times g$ for $8 \mathrm{~min}$. The supernatant $(600 \mathrm{ml})$ was decanted, and the spore concentration was determined with a hemacytometer. The total number of conidia was determined and divided by the number of lesions or the average area of the lesions from which the conidia were washed to obtain the mean number of conidia per lesion and the mean number of conidia per square millimeter of lesion (conidia density), respectively.

Experimental design and statistical analysis. Each cultivar $x$ temperature $x$ leaf wetness combination was replicated three times in each of the three trials of the experiment. Treatments were replicated over time because of the limitation of space in the growth chambers. In the first trial, trees were inoculated on 29 May, 2 June, or 7 June 1995; in the second trial, trees were inoculated on 17, 20, or 23 August 1995; and in the third, trial trees were inoculated on 18,22 , or 27 October 1995. In the first and second trials, 108 trees, 54 of each cultivar, were used, and in the third trial, 72 trees, 36 of each cultivar, were used.

Logistic regression was used to model the probability of disease incidence as a function of cultivar, temperature, leaf wetness duration, and leaf age. For a single leaf, $Y$ was defined as a Bernoulli random variable such that $Y=1$ when disease was present and $Y=$ 0 when disease was absent. The probability that disease occurs, $\pi=$ $P(Y=1)$, was estimated from the data as the proportion of diseased leaves in a particular cultivar $\times$ temperature $\times$ leaf wetness $\times$ leaf age category. The logit of $\pi$ was defined as $\operatorname{logit}(\pi)=\ln [\pi /(1-$ $\pi)$ ], in which "In" represents the natural logarithm function. The parameters in the logistic regression equation $\operatorname{logit}(\pi)=X \beta$ were estimated by maximum likelihood; in which $\boldsymbol{X}$ is a $n \times p$ data matrix and $\beta$ is a $p \times 1$ vector of parameter estimates. Here, the $p$ parameters are estimates of the intercept and the effects of cultivar, temperature, leaf wetness, and leaf age on $\operatorname{logit}(\pi)$. The probability that an individual leaf became infected, given any set of regressors, $x_{i}$ (i.e., any row of $\boldsymbol{X}$ ), in which $i=1$ to $n$, can be estimated using

$$
\pi_{i}=\frac{\exp \left(x_{i}^{\prime} \beta\right)}{1+\exp \left(x_{i}^{\prime} \beta\right)}=\frac{\exp \left(\beta_{0}+\beta_{1} x_{1 i}+\beta_{2} x_{2 i}+\ldots+\beta_{p-1} x_{(p-1) i}\right)}{1+\exp \left(\beta_{0}+\beta_{1} x_{1 i}+\beta_{2} x_{2 i}+\ldots+\beta_{p-1} x_{(p-1) i}\right)}
$$

The odds ratio, $\psi$, provides an interesting and alternative way of interpreting regression coefficients. The odds of disease (in our case) is defined as the ratio of the probability of disease $(\pi)$ to the probability of no disease, $\pi /(1-\pi)$. When two sets of binary data are to be compared, the odds ratio provides a relative measure of the odds of disease in one set relative to that in the other. The odds ratio is easily obtained from the estimated parameters. For example, consider a case in which a single continuous variable (e.g., temperature) is used as an explanatory variable for the incidence of disease. Let $\pi_{1}$ be the probability that disease occurs at some temperature $x$, and let $\pi_{2}$ be the probability that disease occurs at the temperature $x+1$. The odds ratio is calculated as

$$
\psi=\frac{\pi_{2} /\left(1-\pi_{2}\right)}{\pi_{1} /\left(1-\pi_{1}\right)}=\frac{\exp \left[\beta_{0}+\beta_{1}(x+1)\right]}{\exp \left(\beta_{0}+\beta_{1} x\right)}=e^{\beta_{1}}
$$

This, of course, assumes a linear relationship between the explanatory variable, $x$, and $\operatorname{logit}(\pi)$. Similar relationships can be easily 
derived when more than one explanatory variable is used in the model or when the explanatory variable is a factor (5). The interpretation of an odds ratio is simple. An odds ratio greater than 1 indicates an increase in the odds of becoming infected as the independent variable increases; and an odds ratio less than 1 indicates a decrease in the odds of becoming infected as the independent variable increases (15).

Model validity was assessed by visually inspecting plots of the Studentized deviance residuals against the predicted probability of disease incidence. Standard outlier and influence diagnostics were performed. A normal probability plot was used to visually assess the normality assumption (15) of the deviance residuals. Model fit was assessed using the Hosmer and Lemeshow goodness-of-fit test and a logistic regression analogue of the coefficient of determination, $R_{L}^{2}$, of ordinary least squares (OLS) regression.

OLS regression was used to analyze the effect of cultivar, temperature, leaf wetness, and leaf age on the incubation period, infection frequency, lesion size, number of conidia per lesion, and conidia density (i.e., number of conidia per square millimeter of lesion). Each dependent variable, except incubation period, was transformed to stabilize the variance using $\ln ($ dependent variable +1$)$. The mean response of each transformed variable in each cultivar $\times$ temperature $\times$ leaf wetness duration $\times$ leaf age category was calculated. Categories in which no disease developed were excluded from the analysis, since they provide no information about the components of resistance. When analyzing infection frequency, in addi-

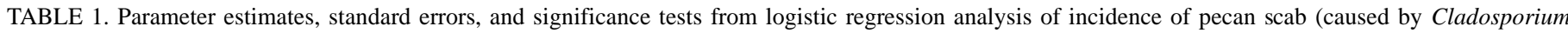
caryigenum) on individual leaves as a function of cultivar, temperature, leaf wetness, and leaf age in three experimental trials

\begin{tabular}{|c|c|c|c|c|c|c|}
\hline Trial $^{a}$ & Variable & Parameter estimate & Standard error & Wald chi-square ${ }^{b}$ & $\operatorname{Pr}>\chi^{2}$ & Odds ratio $^{c}$ \\
\hline \multirow[t]{5}{*}{1} & Intercept & -2.047 & 0.651 & 9.878 & 0.0017 & \\
\hline & Cultivar $^{\mathrm{d}}$ & 2.120 & 0.373 & 32.237 & 0.0001 & 8.331 \\
\hline & Temperature & -0.057 & 0.018 & 10.237 & 0.0014 & 0.945 \\
\hline & Leaf wetness ${ }^{f}$ & 0.091 & 0.011 & 73.069 & 0.0001 & 1.096 \\
\hline & Leaf age & -0.222 & 0.035 & 40.998 & 0.0001 & 0.801 \\
\hline \multirow[t]{5}{*}{2} & Intercept & -0.300 & 2.074 & 0.021 & 0.8852 & \\
\hline & Cultivar & 2.872 & 0.800 & 12.875 & 0.0003 & 17.671 \\
\hline & Temperature & -0.251 & 0.062 & 16.261 & 0.0001 & 0.778 \\
\hline & Leaf wetness & 0.206 & 0.046 & 19.900 & 0.0001 & 1.228 \\
\hline & Leaf age & -0.385 & 0.080 & 23.266 & 0.0001 & 0.680 \\
\hline \multirow[t]{5}{*}{3} & Intercept & 0.308 & 0.787 & 0.153 & 0.6957 & \\
\hline & Cultivar & 0.863 & 0.309 & 7.796 & 0.0052 & 2.369 \\
\hline & Temperature & -0.076 & 0.020 & 15.196 & 0.0001 & 0.927 \\
\hline & Leaf wetness & 0.055 & 0.012 & 21.078 & 0.0001 & 1.056 \\
\hline & Leaf age & -0.204 & 0.035 & 34.423 & 0.0001 & 0.815 \\
\hline
\end{tabular}

a Three independent experiments were performed, each consisting of three replications of each cultivar $\times$ temperature $\times$ leaf wetness duration treatment.

b Wald statistic $=W_{k}=\left[b_{k} /\left(\text { standard error of } b_{k}\right)\right]^{2}$, in which $b_{k}$ is the $k$ th parameter estimate $(k=1,2, \ldots, p)$. $W_{k} \approx \chi^{2}$ with $1 \mathrm{df}$.

c The odds ratio provides a relative measure of disease in one set of binary data relative to that in another set.

${ }^{\mathrm{d}}$ Cultivars Wichita (susceptible) and Sumner (resistant) were used in all three trials.

e Temperature treatments were 15,25 , and $35^{\circ} \mathrm{C}$.

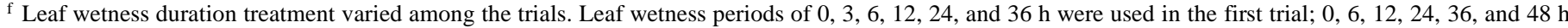
were used in the second trial; and $0,24,36$, and $48 \mathrm{~h}$ were used in the third trial.

${ }^{\mathrm{g}}$ Leaf age measured in days.

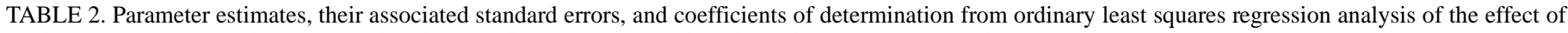
cultivar, temperature, leaf wetness, and leaf age on five components of partial resistance to pecan scab (Cladosporium caryigenum)

\begin{tabular}{|c|c|c|c|c|c|c|c|c|c|}
\hline \multirow{3}{*}{$\frac{\text { Variable }^{\mathrm{a}}}{\text { Incubation period }}$} & \multirow{3}{*}{$\frac{\text { Trial }^{\mathrm{b}}}{1}$} & \multirow{3}{*}{$\begin{array}{c}\text { Model } \\
P \text { value }^{\mathrm{c}}\end{array}$} & \multirow{3}{*}{$\frac{n}{42}$} & \multirow{3}{*}{$\frac{R^{2}}{0.18}$} & \multicolumn{5}{|c|}{ Parameter estimate (standard error of the estimate) } \\
\hline & & & & & \multirow{2}{*}{$\frac{\text { Intercept }}{14.851 * *(3.407)^{\mathrm{h}}}$} & Cultivar $^{\mathrm{d}}$ & \multirow{2}{*}{$\begin{array}{l}\text { Temperature }^{\mathrm{e}} \\
0.068(0.107)\end{array}$} & \multirow{2}{*}{$\begin{array}{c}\text { Leaf wetness }^{\mathrm{f}} \\
-0.066(0.056)\end{array}$} & Leaf age ${ }^{g}$ \\
\hline & & & & & & $(1.307)$ & & & $(0.156)$ \\
\hline & 2 & 0.0077 & 9 & 0.94 & $17.945 * *(2.267)$ & $-4.830 *(1.060)$ & $0.033(0.040)$ & $0.008(0.032)$ & $(0.083)$ \\
\hline & 3 & 0.0081 & 30 & 0.41 & $11.132 * *(2.040)$ & $0.737 \quad(0.603)$ & $-0.059(0.051)$ & $-0.060(0.032)$ & $0.205^{*} \quad(0.077)$ \\
\hline \multirow[t]{3}{*}{ Infection frequency } & 1 & 0.0170 & 41 & 0.28 & $(0.202)$ & $0.229 * *(0.073)$ & $0.005(0.006)$ & $0.003(0.003)$ & $-0.028 * *(0.009)$ \\
\hline & 2 & 0.2419 & 11 & 0.55 & $0.558 \quad(0.259)$ & $0.209 * \quad(0.084)$ & $-0.003(0.005)$ & $-0.002(0.004)$ & $-0.026^{*} \quad(0.010)$ \\
\hline & 3 & 0.0001 & 48 & 0.62 & $0.416 * *(0.138)$ & $0.058 \quad(0.045)$ & $0.007(0.004)$ & $0.001(0.003)$ & $-0.041 * *(0.005)$ \\
\hline \multirow[t]{3}{*}{ Lesion size } & 1 & 0.0126 & 41 & 0.29 & $0.843 \quad(0.556)$ & $0.618 * *(0.202)$ & $-0.008(0.017)$ & $0.005(0.009)$ & $-0.075^{* *}(0.026)$ \\
\hline & 2 & 0.2005 & 11 & 0.58 & $(0.690)$ & $0.445 \quad(0.224)$ & $-0.003(0.013)$ & $0.014(0.010)$ & $-0.042 \quad(0.027)$ \\
\hline & 3 & 0.0001 & 48 & 0.59 & $(0.239)$ & $0.319 * *(0.078)$ & $0.002(0.006)$ & $0.009(0.005)$ & $-0.051 * *(0.009)$ \\
\hline \multirow[t]{3}{*}{ Conidia/lesion } & 1 & 0.0037 & 41 & 0.34 & $(3.397)$ & $4.451 * *(1.234)$ & $-0.091(0.101)$ & $0.025(0.055)$ & $-0.473 * *(0.158)$ \\
\hline & 2 & 0.2665 & 11 & 0.53 & $1.603 \quad(10.175)$ & $5.838 \quad(3.299)$ & $0.133(0.184)$ & $0.020(0.151)$ & $-0.358 \quad(0.392)$ \\
\hline & 3 & 0.0001 & 48 & 0.46 & $(1.930)$ & $2.672 * *(0.630)$ & $0.010(0.050)$ & $0.026(0.040)$ & $-0.236 * *(0.075)$ \\
\hline \multirow[t]{3}{*}{ Conidia density } & 1 & 0.0045 & 41 & 0.31 & (3.007) & $3.830 * *(1.092)$ & $-0.092(0.089)$ & $0.021(0.049)$ & $-0.400 * *(0.140)$ \\
\hline & 2 & 0.3726 & 11 & 0.46 & $0.593 \quad(12.199)$ & (3.953) & $0.150(0.220)$ & $0.020(0.181)$ & -0.297 \\
\hline & 3 & 0.0010 & 48 & 0.40 & $3.807 * \quad(2.076)$ & $2.343 * *(0.678)$ & $-0.005(0.054)$ & $0.013(0.043)$ & $-0.190 * *(0.080)$ \\
\hline
\end{tabular}

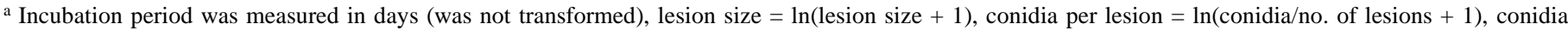
density $=\ln \left(\right.$ conidia $/ \mathrm{mm}^{2}$ of lesion +1$)$, and infection frequency $=\ln \left(\right.$ no. of infections $/ \mathrm{cm}^{2}$ of leaf $)$ were averaged in each cultivar $\times$ temperature $\times$ leaf wetness $\times$ leaf age category. Healthy leaves were not included in the analysis.

b Three independent experiments were performed, each consisting of three replications in each cultivar $\times$ temperature $\times$ leaf wetness combination.

c Achieved significance for regression model.

${ }^{\mathrm{d}}$ Cultivars Wichita (susceptible) and Sumner (resistant) were used in all three trials.

e Temperature treatment included 15,25 , and $35^{\circ} \mathrm{C}$.

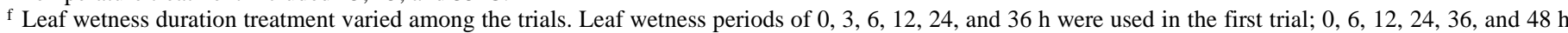
were used in the second trial; and $0,24,36$, and $48 \mathrm{~h}$ were used in the third trial.

$\mathrm{g}$ Leaf age was measured in days.

h $*=$ significant at $P<0.05 ; * *=$ significant at $P<0.01$. 
tion to the previously deleted categories, categories in which lesions never sporulated were also excluded from the analysis. Model validity was assessed using standard residual and outlier analyses. In all regressions (including the logistic), cultivar served as a categorical variable ( $C=1$ for 'Wichita', $C=0$ for 'Sumner').

A correlation analysis was performed to investigate the interrelationship among resistance components. There was no a priori expectation that any pair of resistance components were related in a linear fashion; thus, Kendall's sample rank correlation coefficient $(\tau)$ was chosen, because $\tau$ is capable of detecting nonlinear relationships (9). The coefficient can be calculated as $\tau=2\left(K^{\prime}-K^{\prime \prime}\right)$ / $n(n-1)$, in which $K^{\prime}$ is the number of concordant pairs and $K^{\prime \prime}$ is the number of discordant pairs for the $n(n-1) / 2$ possible set of pairs $\left(X_{i}, Y_{i}\right),\left(X_{j}, Y_{j}\right)$, in which $i<j$. Thus, $\tau$ can be thought of as an average measure of association between the $X \mathrm{~s}$ and $Y$ s where agreement refers to order. All data were analyzed with the statistical package SAS (SAS Institute, Cary, NC).

\section{RESULTS}

Symptoms first appeared 12, 16, and 8 days after inoculation on leaves of both 'Wichita' and 'Sumner' in the first, second, and third trials, respectively. Disease developed in all trials of the experiment. However, disease did not develop on either cultivar at $35^{\circ} \mathrm{C}$, except for the third trial in which one 'Sumner' leaf exposed to $48 \mathrm{~h}$ of leaf wetness developed a few lesions. In the first trial, disease developed on 'Wichita' leaves after a minimum of $12 \mathrm{~h}$ of wetness at $25^{\circ} \mathrm{C}$ and after a minimum of $24 \mathrm{~h}$ of wetness at $15^{\circ} \mathrm{C}$. On 'Sumner' leaves, disease developed after a minimum of $24 \mathrm{~h}$ of wetness at $25^{\circ} \mathrm{C}$ and after a minimum of $36 \mathrm{~h}$ of wetness at $15^{\circ} \mathrm{C}$. In the second trial, disease developed on 'Wichita' leaves after a minimum of $36 \mathrm{~h}$ of wetness at both 15 and $25^{\circ} \mathrm{C}$. On 'Sumner' leaves, disease developed after a minimum of $36 \mathrm{~h}$ of wetness at $15^{\circ} \mathrm{C}$ and after a minimum of $48 \mathrm{~h}$ of wetness at $25^{\circ} \mathrm{C}$. In the third trial, disease developed on 'Wichita' leaves after a minimum of $24 \mathrm{~h}$ of leaf wetness (the shortest leaf wetness period) at both 15 and $25^{\circ} \mathrm{C}$. On 'Sumner' leaves, disease developed after a minimum of $24 \mathrm{~h}$ at $15^{\circ} \mathrm{C}$ and after $36 \mathrm{~h}$ at $25^{\circ} \mathrm{C}$.

Results from logistic regression analysis showed that cultivar, temperature, leaf wetness duration, and leaf age significantly $(P<$ 0.0001 ) affected the incidence of disease in all three trials (Table 1). Residual analysis indicated that the simple model chosen adequately described the relationship between the explanatory variables and $\operatorname{logit}(\pi)$. Although there were some outliers and influential data points in each trial, there was no justification to discard these data from the analysis. These simply represented the natural variability of the system. Within the range of conditions studied, the odds ratio showed that a $1^{\circ} \mathrm{C}$ increase in temperature decreased the odds of a leaf becoming infected by 5.5, 22.2, and 7.3\%; a 1-h increase in leaf wetness duration increased the odds of a leaf becoming infected by $9.6,22.8$, and $5.6 \%$; and a 1 -day increase in leaf age decreased the odds of a leaf becoming infected by 19.9, 32.0, and $18.5 \%$ in the first, second, and third trials, respectively. 'Wichita' leaves were always more susceptible than 'Sumner' (Table 1).

Cultivar and leaf age had a significant effect on lesion size, number of conidia per lesion, and conidia density in trials 1 and 3 but not in trial 2 (Table 2). Lesions on 'Wichita' leaves were primarily dark and circular with diameters ranging from $\approx 0.5$ to $3.5 \mathrm{~mm}$, whereas on 'Sumner' leaves, lesions were typically yellow to light brown and circular with diameters ranging from $\approx 0.5$ to $2.0 \mathrm{~mm}$. In trials 2 and 3, lesions on 'Wichita' leaves produced significantly $(P<0.05)$ more spores per lesion and per unit area of lesion than lesions on 'Sumner' leaves according to two sample $t$ tests (data not shown). In trial 1, the same relationship between lesion size and spore production existed, but at an achieved significance level of $P<0.08$ (data not shown). The effects of cultivar and leaf age on infection frequency varied across trials. In all three trials, as leaf age increased, there were significant $(P<0.05)$ decreases in the infection frequency (Table 2). In general, the incubation period was not significantly influenced by host resistance and leaf age. However, 'Sumner' did have a significantly $(P<0.05)$ longer incubation period in trial 2 , and in trial 3 , the incubation period was significantly longer on older leaves than on younger leaves (Table 2). The incubation period ranged from 8 to 21 days over the three trials for 'Wichita' and from 8 to 23 days over the three trials for 'Sumner'. Temperature and duration of leaf wetness at inoculation had no effect on the incubation period, infection frequency, lesion size, conidia per lesion, or conidia density in any trial (Table 2).

In trials 1 and 3 , the number of conidia per lesion and conidia density were positively correlated $(P<0.05)$ with lesion size for 'Wichita' and 'Sumner' (Table 3, Fig. 1). In all three trials, lesion size (except trial 2), conidia per lesion, and conidia density were all positively correlated $(P<0.05)$ with infection frequency for 'Wichita' (Table 3, Fig. 2). Conidia production and lesion size

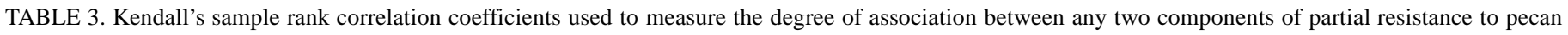
scab (Cladosporium caryigenum) ${ }^{\mathrm{a}}$

\begin{tabular}{|c|c|c|c|c|c|}
\hline Resistance component ${ }^{b}$ & Incubation period & Infection frequency & Lesion size & Conidia per lesion & Conidia density \\
\hline Incubation period & $\cdots$ & $\begin{array}{c}-0.101(30) \\
0.052(8) \\
-0.354(23)^{*}\end{array}$ & $\begin{array}{l}-0.157(30) \\
-0.471(8) \\
-0.373(23)^{*}\end{array}$ & $\begin{array}{c}-0.246(30) \\
0.052(8) \\
0.118(23)\end{array}$ & $\begin{array}{c}-0.251(30) \\
0.052(8) \\
0.250(23)\end{array}$ \\
\hline Infection frequency & $\begin{array}{c}-0.072(10) \\
\text { N/A (1) } \\
-0.700(7)^{*}\end{array}$ & $\ldots$ & $\begin{array}{l}0.623(30)^{*} \\
0.357(86) \\
0.561(31)^{*}\end{array}$ & $\begin{array}{l}0.651(30)^{*} \\
0.643(8)^{*} \\
0.324(31)^{*}\end{array}$ & $\begin{array}{l}0.660(30)^{*} \\
0.643(8)^{*} \\
0.269(31)^{*}\end{array}$ \\
\hline Lesion size & $\begin{array}{c}0.025(10) \\
\text { N/A (1) } \\
0.000(7)\end{array}$ & $\begin{array}{c}0.603(11)^{*} \\
-0.333(3) \\
0.294(17)\end{array}$ & $\cdots$ & $\begin{array}{l}0.887(30)^{*} \\
0.286(8) \\
0.480(31)^{*}\end{array}$ & $\begin{array}{l}0.868(30)^{*} \\
0.286(82) \\
0.338(31)^{*}\end{array}$ \\
\hline Conidia per lesion & $\begin{array}{c}-0.253(10) \\
\text { N/A (1) } \\
-0.117(7)\end{array}$ & $\begin{array}{l}0.710(11)^{*} \\
0.817(3) \\
0.320(17)\end{array}$ & $\begin{array}{c}0.873(11)^{*} \\
-0.817(3) \\
0.398(17)^{*}\end{array}$ & $\ldots$ & $\begin{array}{l}0.972(30)^{*} \\
1.000(8)^{*} \\
0.841(31)^{*}\end{array}$ \\
\hline Conidia density & $\begin{array}{c}-0.076(10) \\
\text { N/A (1) } \\
0.000(7)\end{array}$ & $\begin{array}{l}0.751(11)^{*} \\
0.817(3) \\
0.320(17)\end{array}$ & $\begin{array}{l}0.830(11)^{*} \\
-0.817(3) \\
0.398(17)^{*}\end{array}$ & $\begin{array}{l}0.956(11)^{*} \\
1.000(3) \\
0.967(17)^{*}\end{array}$ & $\cdots$ \\
\hline
\end{tabular}

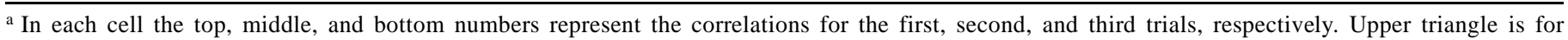
comparison of results made on the cultivar Wichita (susceptible). Lower triangle is for comparisons made on the cultivar Sumner (resistant). Number in

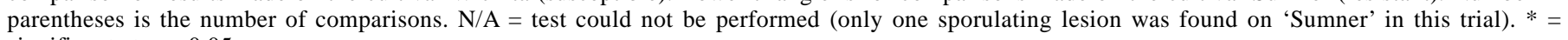
significant at $\alpha=0.05$.

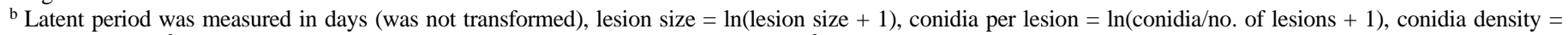

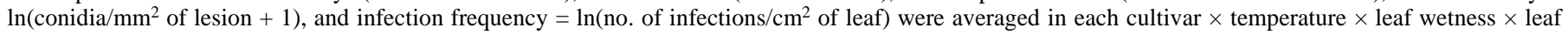
age category. Healthy leaves were not included in the analysis. 
were positively correlated with infection frequency for 'Sumner' only in the first trial (Table 3). In general, there were no significant correlations between the incubation period and any other resistance component for either cultivar (Table 3 ).

Leaf age had a significant effect on the susceptibility of leaves to infection in all trials (Table 1). Results showed that leaves on 'Wichita' were susceptible to infection when inoculated between 2 and 23 days old, and leaves on 'Sumner' were susceptible to infection when inoculated between 2 and 18 days old (Fig. 3). There was a large difference in the distribution of leaf ages among trials (Fig. 3). The mean leaf age was approximately 13, 24, and 11 days in the first, second, and third trials, respectively. In trials 1 and 3, infection frequency, lesion size, conidia per lesion, and conidia density decreased significantly with increasing leaf age for both cultivars (Table 2). This effect was greatest on 'Sumner' leaves (Table 2, Fig. 4). The response of the resistance components in the second trial was variable.

\section{DISCUSSION}

Results from our experiment indicate that host resistance and leaf age were the most influential factors affecting infection of pecan leaves by $C$. caryigenum under the range of temperature and leaf wetness conditions studied. 'Wichita' leaves were susceptible to infection from 2 to 23 days after budbreak. This is consistent with earlier findings that showed leaves on seedlings of 'Wichita' were susceptible to infection from 5 to 21 days after budbreak $(12,26)$. However, the range of ages in which leaves were susceptible to infection was typically much narrower on 'Sumner'. The oldest leaf to become infected was only 18 days old at inoculation. A narrower range of leaf age susceptibility could have significant epidemiological consequences. In a population of plants, a more rapid buildup of resistant leaves would reduce the total number of infections resulting in sporulating lesions and, consequently, reduce

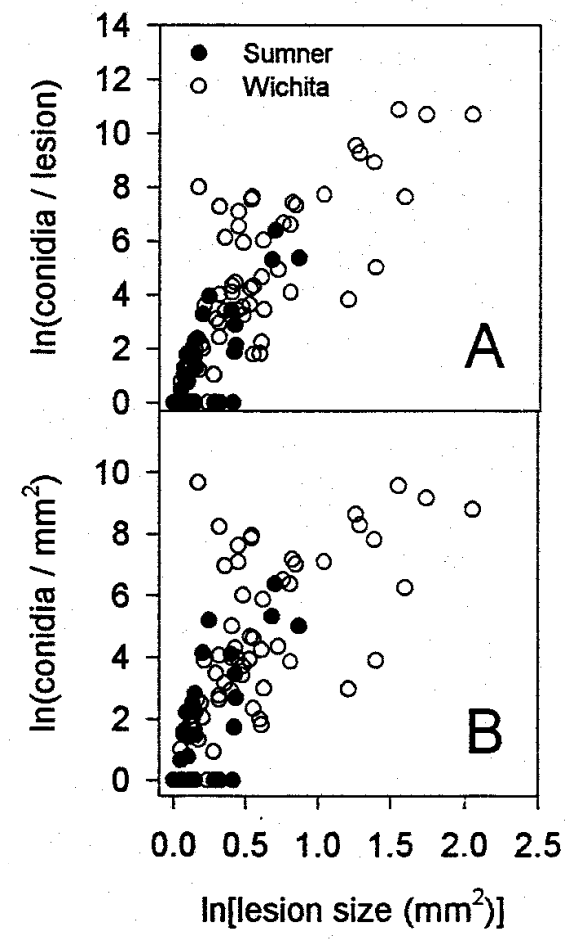

Fig. 1. Relationship A, between lesion size and conidia production per lesion and $\mathbf{B}$, between lesion size and conidia density on susceptible ('Wichita') and partially resistant ('Sumner') pecan leaves following inoculation with conidia of Cladosporium caryigenum and exposure to different combinations of temperature and wetness duration. Data points are means of each treatment combination of cultivar, temperature, wetness duration, and leaf age from each of three experimental trials. the rate of epidemic development. For example, partial resistance to rice blast (Pyricularia oryzea) has been associated with cultivars that produce leaves that mature rapidly (20).

Disease incidence was noticeably lower in the second trial. In this trial, the average leaf age was approximately twice that of the first and third trials; thus, it is likely that many of the leaves escaped infection simply because they were too old. Disease failed to develop on those leaves exposed to wetness periods of the same duration as leaves in the first and third trials that did develop symptoms. Thus, there is indirect evidence to support that, as leaves age, longer periods of leaf wetness are required for infection. However, measuring leaf age on a calendar schedule may not be the most accurate method of determining the age of a leaf and, hence, the state of susceptibility of the leaf to scab infection. Various growth stages of the pecan such as time of budbreak are strongly influenced by fluctuations in temperature (24). Thus, physiological age, as measured in degree-days, may be a more appropriate means of quantifying leaf age. In trial 3, leaves of 'Sumner' were susceptible to infection approximately 3 to 5 days longer than leaves in the previous trials (Fig. 3). Nighttime temperatures in the greenhouse around the time of the third trial were approximately 5 to $7^{\circ} \mathrm{C}$ cooler compared with the nighttime temperatures around the first and second trials. Thus, it is likely that leaves matured more rapidly in the warmer conditions of the first and second trials than the third and, consequently, became resistant to infection more quickly than leaves in the third trial.

In all three trials, cooler temperatures and longer leaf wetness periods at inoculation favored infection of pecan leaves by $C$. caryigenum. These results are consistent with previous studies conducted on seedlings of 'Wichita' $(12,26)$ and were not unexpected, because $C$. caryigenum has a relatively cool optimum growth temperature of 22 to $25^{\circ} \mathrm{C}$ (14). However, the range of temperatures and leaf wetness durations at which infection occurs differs somewhat from earlier findings of Gottwald (12). In our study, disease

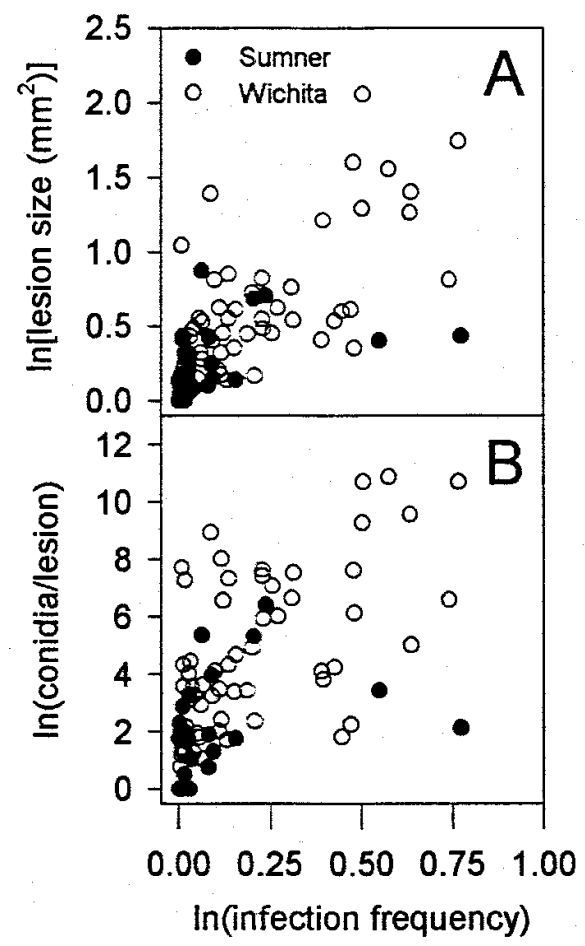

Fig. 2. Relationship A, between lesion size and infection frequency (lesions per unit leaf area) and $\mathbf{B}$, between conidia production per lesion and infection frequency on susceptible and partially resistant ('Sumner') pecan leaves following inoculation with conidia of Cladosporium caryigenum and exposure to different combinations of temperature and wetness duration. Data points are means of each treatment combination of cultivar, temperature, wetness duration, and leaf age from each of three experimental trials. 
did not develop at $35^{\circ} \mathrm{C}$ (with the exception of one 'Sumner' leaf) or after leaf wetness periods less than $12 \mathrm{~h}$. In Gottwald's study, 'Wichita' seedlings rather than grafted material were used and, after the prescribed wetness period, the seedlings were moved into a temperature-controlled $\left(\approx 24\right.$ to $28^{\circ} \mathrm{C}$ ), high-humidity chamber to allow disease development. The postinoculation conditions in the first and second trials of our study consisted of daily fluctuations of relative humidity between 50 and $98 \%$ and temperature fluctuations between 24 and $34^{\circ} \mathrm{C}$; in the third trial, daily fluctuations of relative humidity were between 30 and $98 \%$ and temperature
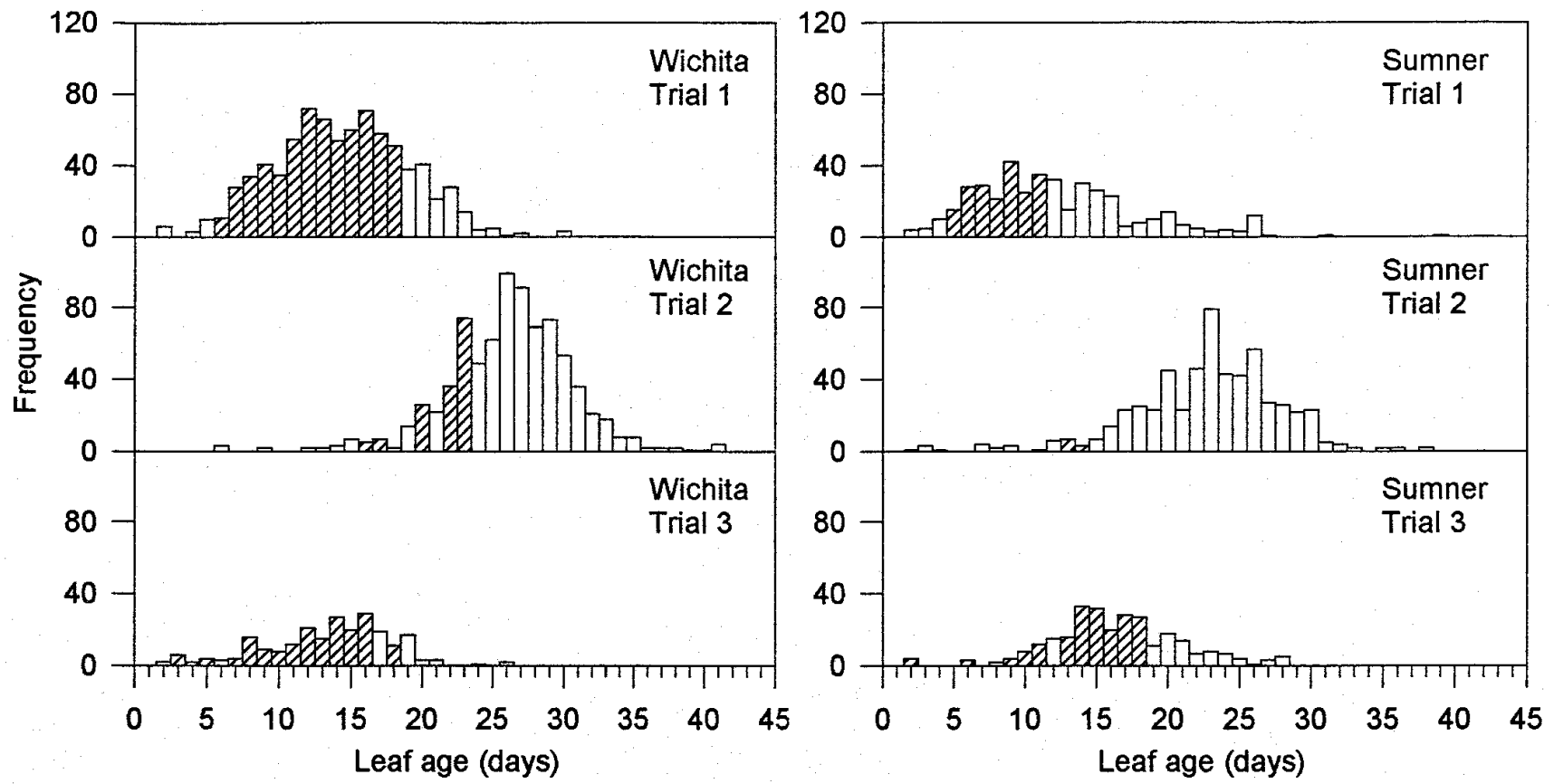

Fig. 3. Frequency distributions of age of leaves of susceptible ('Wichita') and partially resistant ('Sumner') pecan trees when inoculated with conidia of Cladosporium caryigenum. Shaded bars indicate ages of leaves that developed symptoms of pecan scab following incubation.
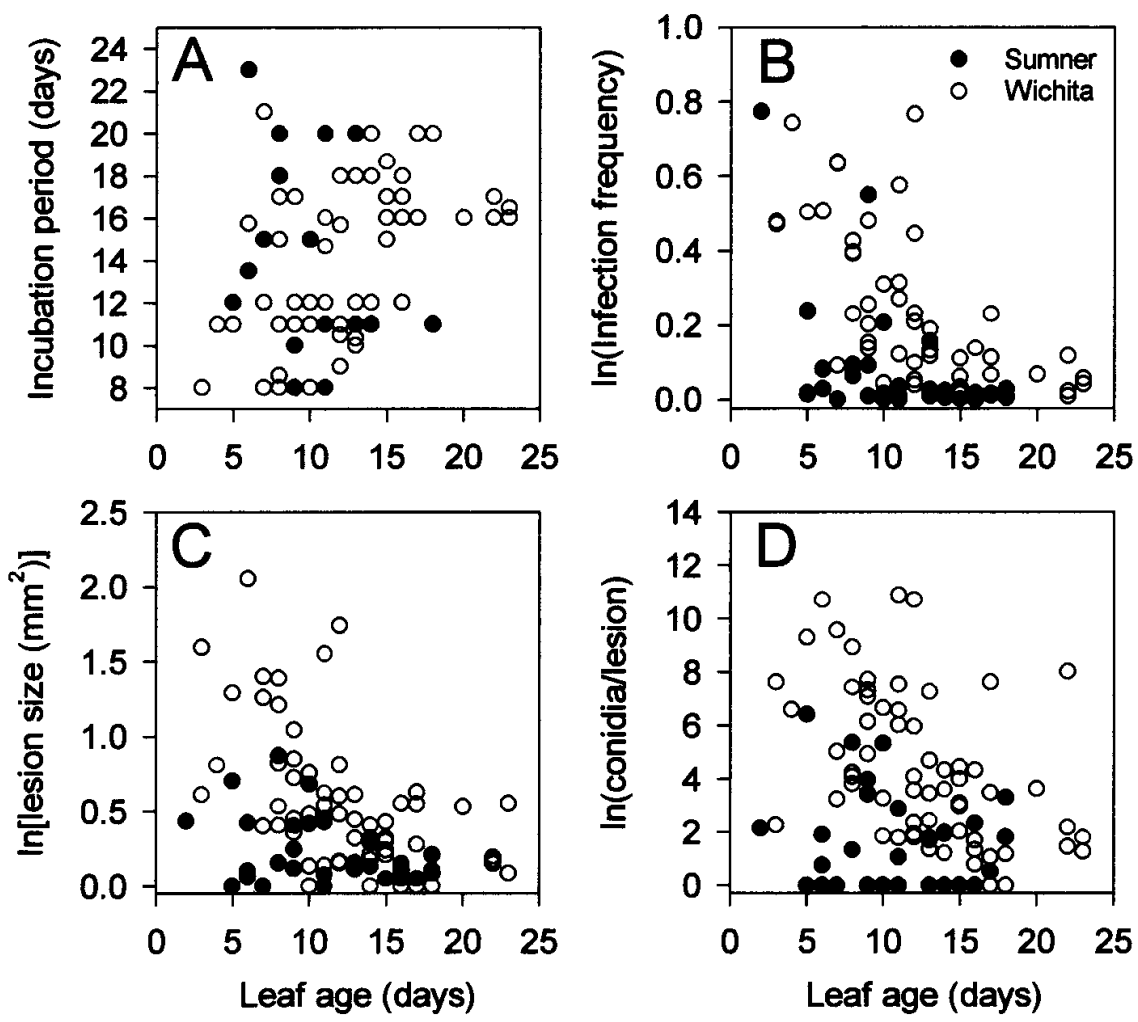

Fig. 4. Relationship between leaf age and $\mathbf{A}$, incubation period; $\mathbf{B}$, infection frequency (lesions per unit leaf area); $\mathbf{C}$, lesion size; and $\mathbf{D}$, conidia per lesion on susceptible ('Wichita') and partially resistant ('Sumner') pecan leaves following inoculation with conidia of Cladosporium caryigenum and exposure to different combinations of temperature and wetness duration. Data points are means of each treatment combination of cultivar, temperature, wetness duration, and leaf age from each of three experimental trials. 
fluctuations were between 17 and $28^{\circ} \mathrm{C}$. Postinoculation conditions have been shown to influence disease development in some pathosystems (25). Thus, the observed differences in disease development between the two studies may have been due to differential development of the pathogen on seedlings and cultivars or the influence of postinoculation conditions on development of disease.

The choice of inoculation conditions and cultivars undoubtedly influenced the results of our experiment. The experimental conditions were chosen to reflect (i) a broad range of conditions at which C. caryigenum is able to infect susceptible pecan foliage (this information was obtained through preliminary studies [26,27] in combination with the work of Gottwald [12]) and (ii) typical environmental conditions encountered in southeastern pecan orchards. It is important to emphasize that the logistic regression model is descriptive only within the range of conditions and cultivars tested (this, of course, is true of all models). However, we believe that, although different combinations of inoculation conditions and cultivars may produce different parameter estimates, the general trends of the effects of host resistance, leaf age, temperature, and leaf wetness will remain unchanged.

Analysis of resistance components showed that the incubation period, number of infections, size of lesions, and degree of sporulation were not significantly influenced by temperature and duration of leaf wetness at inoculation (Table 2). Although the results presented in Table 2 show a high degree of variability, the resistance components, except for incubation period, were primarily influenced by the level of host resistance and the age of the leaf. Older leaves of both cultivars tended to have fewer infections and smaller, less densely sporulating lesions. It was clear that the magnitude of these effects was greatest on 'Sumner' (i.e., significant cultivar effect). This finding is consistent with an earlier study on pecans in which susceptible seedlings had larger lesions and produced significantly more conidia than seedlings from less susceptible cultivars (27). Similar trends were found for foliar diseases on resistant cultivars of potato (18).

Yates et al. (32) found that the frequency of appressoria formation from germinated $C$. caryigenum conidia did not differ significantly on either immature or mature leaves of the susceptible cultivar Wichita and the resistant cultivar Elliott. However, they found that subcuticular hyphae developed from only $50 \%$ of the appressoria on susceptible 'Wichita' leaves versus $<2 \%$ on susceptible 'Elliott' leaves and that mature leaves from both cultivars were equally able to suppress the development of subcuticular hyphae. Thus, it was not unreasonable to find that infection frequency and incubation period were very similar on the most susceptible leaves of both 'Wichita' and 'Sumner' (e.g., trial 3), because the mechanisms behind resistance in the pecan do not seem to influence conidia germination and appressoria formation (32). The response of 'Sumner' leaves to pathogen attack was manifested in postpenetration events such as lesion expansion and conidia production, which agrees with the findings of Yates et al. (32).

On leaves where disease developed, the frequency of infections, lesion size, and spore production were all positively correlated with each other (Table 3, Figs. 1 and 2). In most cases, there were significant differences between cultivars; that is, 'Wichita' leaves had more infections and thus larger, more densely sporulating lesions. Careful interpretation of these results needs to be stressed. In the first and second trials, but not the third, significant differences in infection frequency between the two cultivars were observed (Table 2 ). In the third trial, many leaves of both cultivars were considered very susceptible to infection (Fig. 3). This result suggests that the level of host resistance (i.e., the effect of cultivar) did not influence the frequency of infections when leaves were considered very susceptible on both cultivars. However, in all trials, disease was the result of a single inoculation. This is important, because the compound leaves of pecan age at different rates; leaflets at the distal end of the leaf are younger and, therefore, more susceptible to infection than leaflets at the proximal end. The proximal leaflets of moderately aged leaves can be immune to infection, while the distal leaflets are still very susceptible. This obviously has a great impact on the number of possible infections, because only a portion of the leaflets may be susceptible to infection at the time of inoculation. Thus, the number of infections is bound to be much lower when leaves are inoculated once compared with an orchard in which multiple inoculations occur. Although results demonstrate that differences in infection frequency exist between 'Wichita' and 'Sumner', the range of values for infection frequency obtained in this experiment may not adequately reflect what is possible under field conditions.

It should be noted that differences in the susceptibility to scab infection between cultivars may be due to pathogenic specialization in $C$. caryigenum. It has been shown that populations of the fungus differ in their ability to infect certain pecan genotypes (6, 8). However, scab lesions observed on 'Sumner' trees inoculated in the greenhouse were similar to those found on 'Sumner' in the orchard. The similarity in lesion characteristics between artificially inoculated and naturally inoculated leaves of 'Sumner' is one indication that the isolates used throughout the study were similar in aggressiveness to isolates found in commercial orchards.

Our study demonstrated that the susceptible and partially resistant cultivars required similar temperature and wetness conditions for infection, but appearance and characteristics of lesions were notably different on the two cultivars. Interestingly, the most susceptible leaves of both cultivars seemed to be equally susceptible to infection by the pathogen. However, 'Sumner' leaves became resistant to infection more quickly than 'Wichita' leaves, which remained susceptible for at least 1 week longer than 'Sumner' leaves. After infection, the pathogen was able to easily colonize and sporulate on 'Wichita' leaves, whereas on 'Sumner' leaves, pathogen colonization was hindered, which resulted in smaller, less densely sporulating lesions.

The appearance of symptoms on resistant cultivars can be misleading. The atypical yellow to light-brown scab lesions that are often found on more resistant pecan cultivars $(26,31)$ are often regarded as unimportant or may not be recognized as pecan scab because low levels of disease incidence may cause little, if any, damage. We have shown that on 'Sumner', a cultivar considered to be very resistant to scab, $C$. caryigenum is able to sporulate, albeit at low levels, and thus reproduce on a resistant host. Therefore, over many years of selection for scab isolates that can infect and reproduce on the resistant cultivar, levels of inoculum may build up to a point at which disease becomes limiting to production. Eventually, this may result in the loss of a productive cultivar, as has been shown with many cultivars in the past that were considered resistant or immune to scab when first introduced $(4,23)$.

\section{LITERATURE CITED}

1. Bertrand, P. F. 1995. 1994 Georgia Plant Disease Loss Estimates. The University of Georgia Cooperative Extension Service, University of Georgia, Athens. Path. 95-007.

2. Bertrand, P. F. 1996. 1995 Georgia Plant Disease Loss Estimates. The University of Georgia Cooperative Extension Service, University of Georgia, Athens. Path. 96-007.

3. Butler, D. R., Wadia, K. D. R., and Jadhav, D. R. 1994. Effects of leaf wetness and temperature on late leaf-spot infection of groundnut. Plant Pathol. 43:112-120.

4. Cole, J. R., and Gossard, A. C. 1956. Increased virulence of scab (Cladosporium effusum Wint. Demaree) on Stuart pecan in Mississippi and its presence in Louisiana. Plant Dis. Rep. 40:1120.

5. Collett, D. 1991. Modelling Binary Data. Chapman \& Hall, London.

6. Converse, R. H. 1960. Physiologic specialization of Fusicladium effusum and its evaluation in vitro. Phytopathology 50:527-531.

7. Coutinho, T. A., Rijkenberg, F. H. J., and van Asch, M. A. J. 1994. The effect of leaf age on infection of Coffea genotypes by Hemileia vastatrix. Plant Pathol. 43:97-103.

8. Demaree, J. B. 1929. Behavior of Cladosporium effusum (Wint.) Demaree on some varieties of pecan. J. Agric. Res. 38:363-371.

9. Gibbons, J. D. 1985. Nonparametric Methods for Quantitative Analysis. 
2nd ed. American Sciences Press, Inc., Columbus, OH.

10. Gottwald, T. R. 1982. Spore discharge by the pecan scab pathogen, Cladosporium caryigenum. Phytopathology 72:1193-1197.

11. Gottwald, T. R. 1982. Taxonomy of the pecan scab fungus Cladosporium caryigenum. Mycologia 74:382-390.

12. Gottwald, T. R. 1985. Influence of temperature, leaf wetness period, leaf age, and spore concentration on infection of pecan leaves by conidia of Cladosporium caryigenum. Phytopathology 75:190-194.

13. Kari, A. G., and Griffiths, E. 1993. Components of partial resistance of barley to Rynchosporium secalis: Use of seedling tests to predict field resistance. Ann. Appl. Biol. 123:545-561.

14. Latham, A. J., and Rushing, A. E. 1988. Development of Cladosporium caryigenum in pecan leaves. Phytopathology 78:1104-1108.

15. Menard, S. 1995. Applied Logistic Regression Analysis. Sage University paper series on Quantitative Applications in the Social Sciences, 07-106. Sage University, Thousand Oaks, CA.

16. Neervoort, W. J., and Parlevliet, J. E. 1978. Partial resistance of barley to leaf rust, Puccinia hordei. V. Analysis of the components of partial resistance in eight barley cultivars. Euphytica 27:33-39.

17. Parlevliet, J. E. 1979. Components of resistance that reduce the rate of epidemic development. Annu. Rev. Phytopathol. 17:203-222.

18. Pelletier, J. R., and Fry, W. E. 1989. Characterization of resistance to early blight in three potato cultivars: Incubation period, lesion expansion, and spore production. Phytopathology 79:511-517.

19. Pretorius, Z. A., and Kemp, H. J. 1990. Effects of growth stage and temperature on components of resistance to leaf rust in wheat genotypes with Lr26. Plant Dis. 74:631-635.

20. Rouman, E. C., Bonman, J. M., and Parlevliet, J. E. 1992. Leaf age related partial resistance to Pyricularia oryzae in tropical lowland rice cultivars as measured by the number of sporulating lesions. Phytopathology 82:1414-1417.
21. Rufty, R. C., and Main, C. E. 1989. Components of partial resistance to blue mold in six tobacco genotypes under controlled environmental conditions. Phytopathology 79:606-609.

22. Scherm, H., and van Bruggen, A. H. C. 1994. Effects of fluctuating temperatures on the latent period of lettuce downy mildew (Bremia lactucae). Phytopathology 84:853-859.

23. Sparks, D. 1992. Pecan Cultivars: The Orchards Foundation. Pecan Production Innovations, Watkinsville, GA.

24. Sparks, D. 1993. Chilling and heating model for pecan budbreak. J. Am. Soc. Hortic. Sci. 118:29-35.

25. Trapero-Casas, A., and Kaiser, W. J. 1992. Influence of temperature, wetness period, plant age, and inoculum concentration on infection and development of ascochyta blight of chickpea. Phytopathology 82:589-596.

26. Turechek, W. W. 1995. Effects of host resistance, temperature, and leaf wetness on the development of pecan scab. M.S. thesis. University of Georgia, Athens.

27. Turechek, W. W., and Reynolds, K. L. 1995. Effects of partial host resistance and leaf wetness duration on the development of pecan scab. (Abstr.) Phytopathology 85:1149.

28. Vanderplank, J. E. 1968. Plant Diseases: Epidemics and Control. Academic Press, New York.

29. Welty, R. E., and Barker, R. E. 1992. Latent period responses of stem rust in tall fescue incubated at four temperatures. Crop Sci. 32:589-592.

30. Wilson, L. L., Madden, L. V., and Ellis, M. A. 1990. Influence of temperature and wetness duration on infection of immature and mature strawberry fruit by Colletotrichum acutatum. Phytopathology 80:111-116.

31. Yates, I. E., and Cason, K. M. T. 1992. Why do leaves of Desirables not Elliotts become infected with scab? Pecan Grower 4:11-13.

32. Yates, I. E., Maxey, D., Lee, S., Sparks, D., and Reilly, C. C. 1996. Developing the pecan scab fungus on susceptible and resistant host and nonhost leaves. J. Am. Soc. Hortic. Sci. 121:350-357. 